\title{
Experimental Study on Irrigation Uniformity Using Low Pressure Single Set Sprinkler System
}

\author{
Suhaimi Hassan, Shahrul Ashyraf, M. Faizairi and Kee Kok Eng \\ Department of Mechanical Engineering, University of Technology PETRONAS (UTP), Perak, Malaysia
}

Corresponding Author: Suhaimi Hassan, Department of Mechanical Engineering, University of Technology PETRONAS, 32610 Seri Iskandar, Perak, Malaysia.

Tel: +605-3687153, Fax: +905-3656461, E-mail: suhaimiha@utp.edu.my

Received date: 23 March 2018, Accepted date: 28 May 2018, Online date: 18 June 2018

Copyright: (C) 2018 Suhaimi Hassan et al. This is an open-access article distributed under the terms of the Creative Commons Attribution License, which permits unrestricted use, distribution, and reproduction in any medium, provided the original author and source are credited.

\begin{abstract}
Sprinkler irrigation system performance is measured by its irrigation uniformity where this factor is depending on several design factors such as operating pressure, nozzle diameter and riser height. An experimental study was conducted to investigate the effect on the combination of parameters towards the irrigation uniformity including the wetted diameter (WD), Coefficient of Uniformity (CU\%) and Distribution Uniformity (DU\%). In order to determine the optimum combinations of operating pressure, riser height and nozzle diameter, five operating pressures between 80 to $240 \mathrm{kPa}$, five riser heights between 0.5 to $1.5 \mathrm{~m}$, and two nozzle diameters of 3 and $4 \mathrm{~mm}$ were used in a single sprinkler system. To measure the irrigation uniformity, catch cans were used to collect water distributed by sprinkler and the result for CU and DU were calculated from the data obtained. Result obtained showed that the higher the operating pressure, riser height and nozzle diameter, the percentage of CU and DU become higher. While for wetted diameter, it is increased when the operating pressure and riser height is increased but decreased when bigger nozzle diameter is used. CU of 65.48 to $83.47 \%$ and 66.67 to $91.67 \%$, and DU of 60.38 to $77.97 \%$ and 62.22 to $88.89 \%$ were obtained under different combinations respectively. While, wetted diameter of 11.22 to $15.99 \mathrm{~m}$ and 8.82 to $12.23 \mathrm{~m}$ were achieved under respective combinations. Therefore, for achievement the optimum performance, it is recommended that the sprinkler irrigation system operated at the best combinations of $240 \mathrm{kPa}$ operating pressure with $1.25 \mathrm{~m}$ riser height and $4 \mathrm{~mm}$ nozzle diameter size.
\end{abstract}

Key words: Coefficient uniformity; Distribution uniformity; Irrigation; Sprinkler system.

\section{INTRODUCTION}

Sprinkler irrigation system is a system to provide irrigation used for agriculture, crops and also for recreation as cooling system. Sprinkler system for irrigation is recognize as a method of applying irrigation water that is similar to natural rainfall concept. It also an adaptable way in providing various crops with uniform distribution of water application over wide range of topographic and soil condition.

The operating pressure, riser height, number and diameter of the nozzles, sprinkler model, environmental conditions, arrangement of the sprinkler and the spacing are the main factors that affect the uniformity of water distribution [1-4]. Uniformity of water distributions from the sprinkler system usually are being measured from field tests, also from the basic calculation of the important performance indicators which includes the combination of application rate and coefficient of uniformity (CU) [5]. The water supply, pumping equipment, mainlines and the lateral pipelines should be well designed and arranged so that the water resources can be uniformly distributed. A proper design of the sprinkler irrigation system will address uniform irrigation application in a timely manner which is also able to minimize water losses and damage to soil, water and crops.

According to Pair et al [6], the performance of sprinkler irrigation system depends upon the operating pressure, nozzle size and type of sprinkler used, the general design selection of the lateral size should follow this rule which to limit the total pressure loss to a minimum of $20 \%$ of the pressure at the entrance to the lateral. The most effective factor on the irrigation uniformity is operating pressure.

Recently, most of the sprinkler system used in agriculture industry are using high operating pressure in order to increase the productivity and quality of the crops. Previous study on the sprinkler irrigation system has conclude that as the operating pressure for the sprinkler system increased, it will result in more water usage, high pressure pump is required and therefore will increase the pumping cost. Also, too high operating pressure will produce fogging and irregular turning on the sprinkler. In order to reduce the energy consumption, reduce water usage and lowering operating cost, sprinkler system should operate at lowest operating pressure at which the uniformity of water application and the system efficiency can be achieved. This study will be using the approach of lowering the operating pressure for the sprinkler irrigation system to find out the suitable pressure with the combination of some other variables which are the nozzle diameter and the sprinkler height. The drainage issues which happened due to over irrigation or seepage losses can also be avoided using this sprinkler irrigation [7].

\section{Objectives:}

This project is an experimental analysis will involve an experimental study on the performance of sprinkler system under various operating pressure, riser height and nozzle diameter with the objective as mentioned as following:

1. To study the usage of the sprinkler system in agriculture industry

2. To investigate the effect of the pressure towards the performance of sprinkler system

3. To propose the optimum pressure for the use in the sprinkler system 


\section{MATERIALS AND METHODS}

This study was conducted at the Department of Mechanical Engineering, University Technology PETRONAS in Perak, Malaysia. A single nozzle impact sprinkler of full circle rotation was used in this study. This system consisted of a water tank, centrifugal water pump, control valve, pressure gauge, sprinklers and PVC pipe. The main line of the system had $15 \mathrm{~mm}$ diameter of lateral and risers. Different operating pressures ranging from 80 to $240 \mathrm{kPa}$ were categorized as low pressure sprinkler. Five difference pressures were selected from this range which are $80 \mathrm{kPa}, 120 \mathrm{kPa}, 160 \mathrm{kPa}, 200 \mathrm{kPa}$ and $240 \mathrm{kPa}$. The diameter of the nozzle size used are $3 \mathrm{~mm}$ and $4 \mathrm{~mm}$. The single nozzle type of sprinklers was selected from single manufacturer. It is a plastic impulse sprinkler with full circle coverage. Different riser height was used which are $0.5 \mathrm{~m}, 0.75 \mathrm{~m}, 1.0 \mathrm{~m}, 1.25 \mathrm{~m}$ and $1.5 \mathrm{~m}$. The outdoor test was conducted using catch cans method. A number of 8 graduated catch-cans with $80 \mathrm{~mm}$ diameter and $90 \mathrm{~mm}$ height were located within the sampling area. The distance between catch cans is $2.0 \mathrm{~m}$ apart and are arranged in square pattern.

\subsection{Water Distribution Uniformity:}

Water distribution uniformity is the measurable index of the degree of uniformity obtained from sprinkler operating condition. It is a statistical measure on how uniform water is being distributed over the land. Two of most widely used uniformity coefficient were as following.

Christiansen's coefficient of uniformity is given by Christiansen J.E. [8]:

$C U=100 *\left[1-\frac{\sum_{i=1}^{n}\left|V_{i}-\bar{V}\right|}{\sum_{i=1}^{n} V_{i}}\right]$

Where:

individual catch can measurement, $\mathrm{mm}$

average depth of application over all catch can measurement, $\mathrm{mm}$

Distribution Uniformity is given by Merriam, J. L., and Keller, J. [9]:

$D U=100 * \frac{\overline{V_{l q}}}{\bar{V}}$

Where:

average of the lowest one-fourth of catch can measurement, mm

average depth of application over all catch can measurement, $\mathrm{mm}$

\subsection{Sprinkler Irrigation System Layout:}

Figure 1 shows the sprinkler irrigation system developed using CATIA software. The catch-cans were located around the sprinkler as shown in Figure 2. The system was run for 20 minutes for each run and then the caught volumes were measured. The catch cans data was used to determine uniformity coefficients. The actual arrangement of the sprinkler irrigation system is shown in Figure 3.

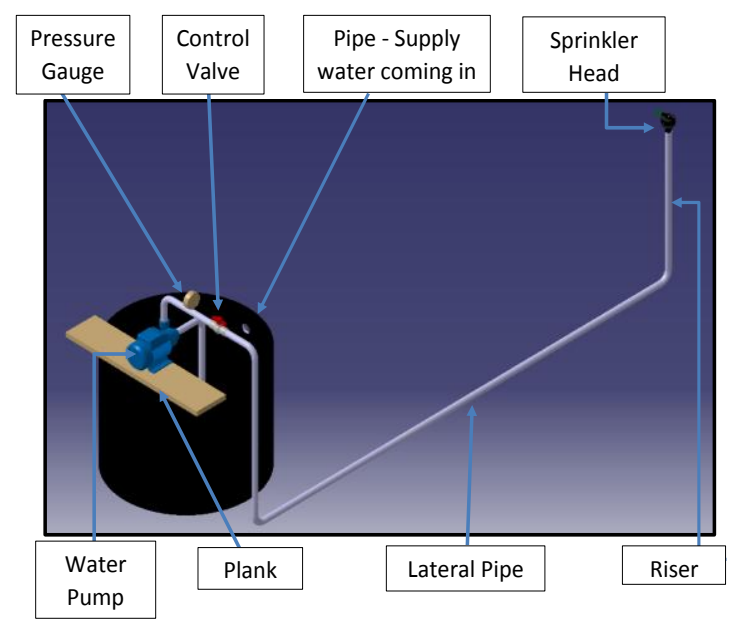

Fig. 1: Single Sprinkler Set Irrigation Diagram in CATIA.
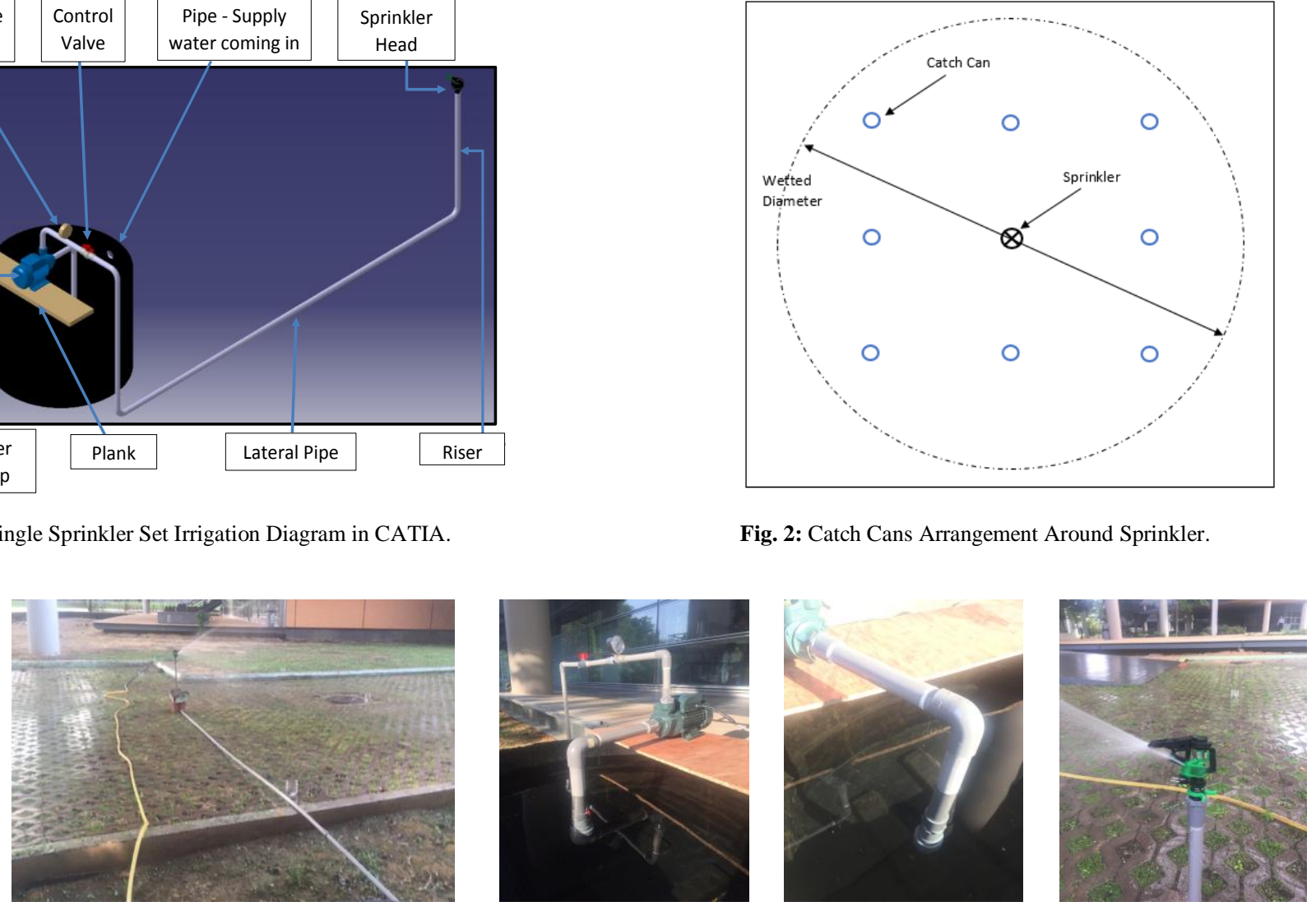

Fig. 2: Catch Cans Arrangement Around Sprinkler.

Fig. 3: General Overview of Sprinkler Irrigation System. 


\section{RESULTS AND DISCUSSIONS}

In this study, comparison on the sprinkler performance was made between different operating pressure, nozzle diameter and riser height. The effect of these different parameters on the wetted diameter, Coefficient of Uniformity (CU) and Distribution Uniformity (DU) were presented here.

\subsection{Wetted Diameter:}

Based on the result obtained, the average wetted diameter is increasing when the operating pressure and riser height are increased. The data on the variation of the average wetted diameter collected is tabulated in Table 1.

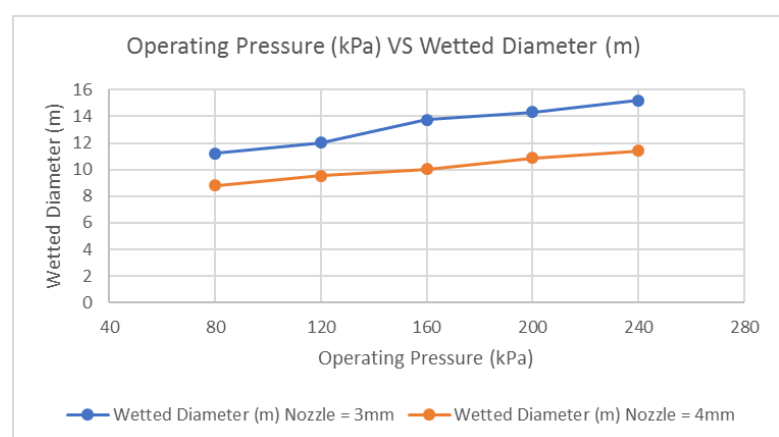

Fig. 4: Wetted Diameter at Riser Height of $0.50 \mathrm{~m}$.

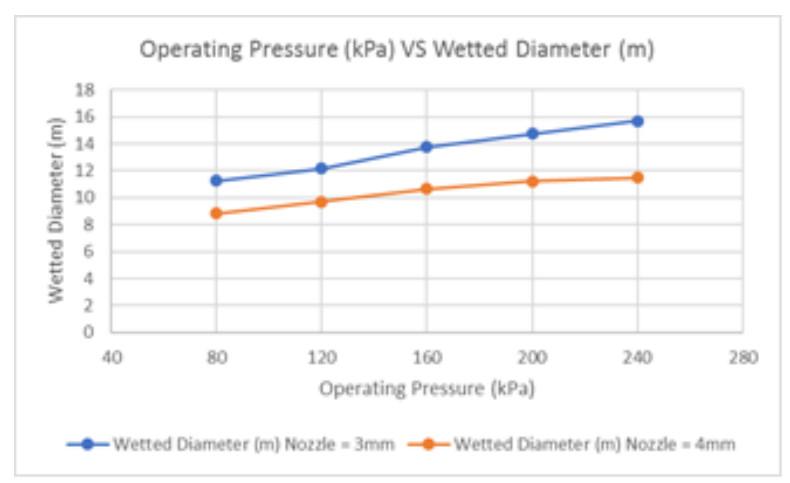

Fig. 6: Wetted Diameter at Riser Height of $1.00 \mathrm{~m}$.

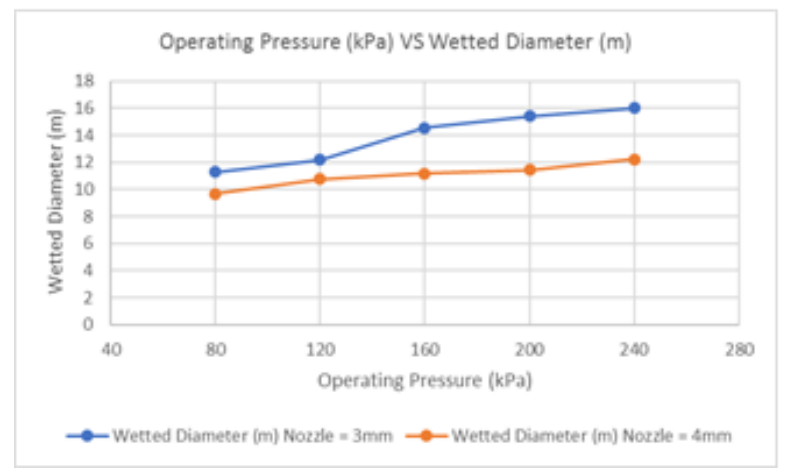

Fig. 8: Wetted Diameter at Riser Height of $1.50 \mathrm{~m}$.

The results for the average wetted diameter shows that the wetted diameter produced by the sprinkler is increase with increasing pressure and riser height. But, the wetted diameter is decreasing when the nozzle diameter is being increased from $3 \mathrm{~mm}$ to 4 mm because with the small nozzle at higher riser height, the water can be distributed with further distance.

So, from the graphs plotted, it can be observed that the largest wetted diameter which is $15.99 \mathrm{~m}$ is produced at peak operating pressure, $240 \mathrm{kPa}$ and riser height, $1.50 \mathrm{~m}$ for $3 \mathrm{~mm}$ nozzle diameter. The lowest value of wetted diameter for $3 \mathrm{~mm}$ nozzle diameter occurs at the operating pressure of $80 \mathrm{kPa}$ and $0.50 \mathrm{~m}$ riser height.

As compared to the $3 \mathrm{~mm}$ sprinkler nozzle diameter, the experiment that run using $4 \mathrm{~mm}$ nozzle diameter produce much smaller wetted diameter. The highest wetted diameter for $4 \mathrm{~mm}$ nozzle diameter also occurs at the peak operating pressure of and riser height which is $240 \mathrm{kPa}$ and $1.50 \mathrm{~m}$ respectively.

\subsection{Coefficient of Uniformity $(C U)$ and Distribution Uniformity $(D U)$ :}

Results for the coefficient of uniformity (CU) and distribution uniformity (DU) is tabulated in the Table 2. It is calculated based on the amount of water caught in the catch can and using the Eqn. (1) and Eqn. (2). Graphs for CU and DU also have been plotted as shown in Figure 9 until Figure 18. 
Citation: Suhaimi Hassan, et al., 2018. Experimental Study on Irrigation Uniformity Using Low Pressure Single Set Sprinkler System. Journal of Applied Sciences Research., 14(3): 1-5.

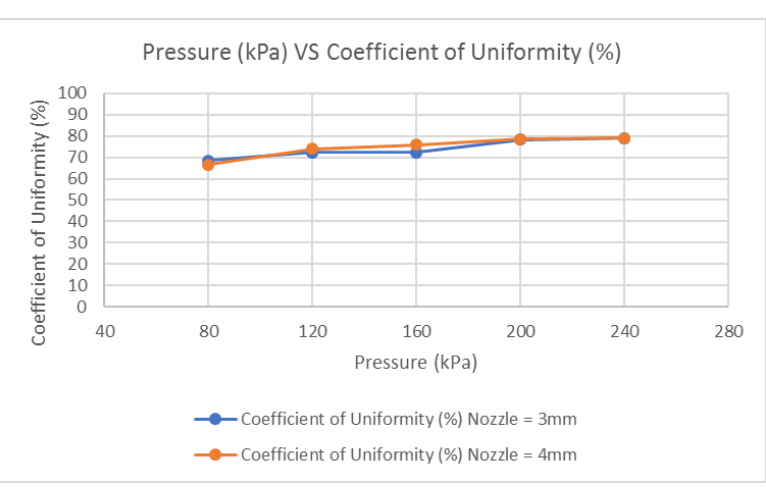

Fig. 9: Coefficient of Uniformity at Riser Height of $0.50 \mathrm{~m}$.

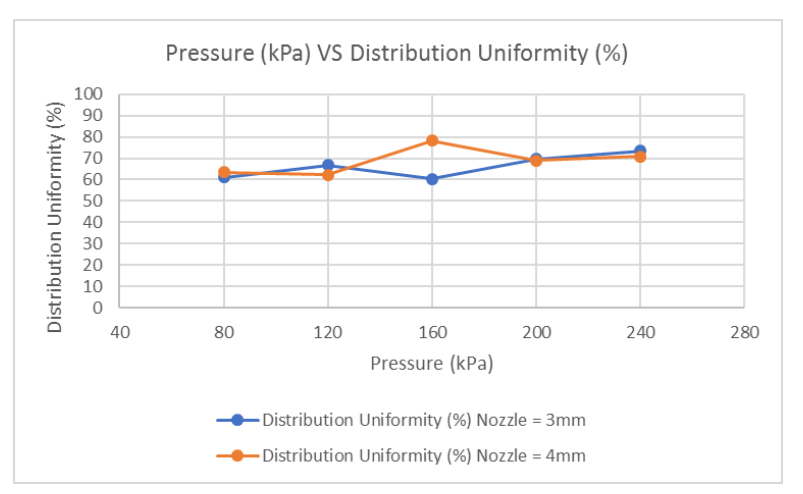

Fig. 10: Distribution Uniformity at Riser Height of $0.50 \mathrm{~m}$.

From Figure 9, it is observed that there is not much difference in the percentage of Coefficient of Uniformity (CU) between 3 mm and 4 mm nozzle diameter which means that at $0.50 \mathrm{~m}$ riser height, the $\mathrm{CU}$ is not so affected when the nozzle diameter is changed.

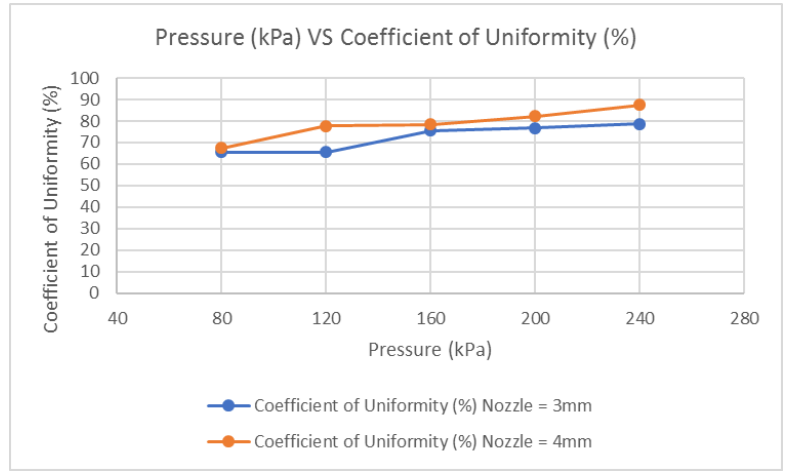

Fig. 11: Coefficient of Uniformity at Riser Height of $0.75 \mathrm{~m}$.

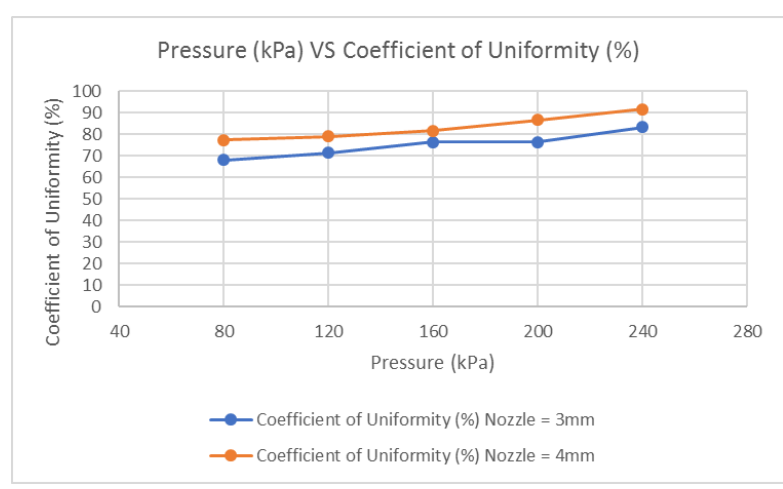

Fig. 13: Coefficient of Uniformity at Riser Height of $1.00 \mathrm{~m}$.

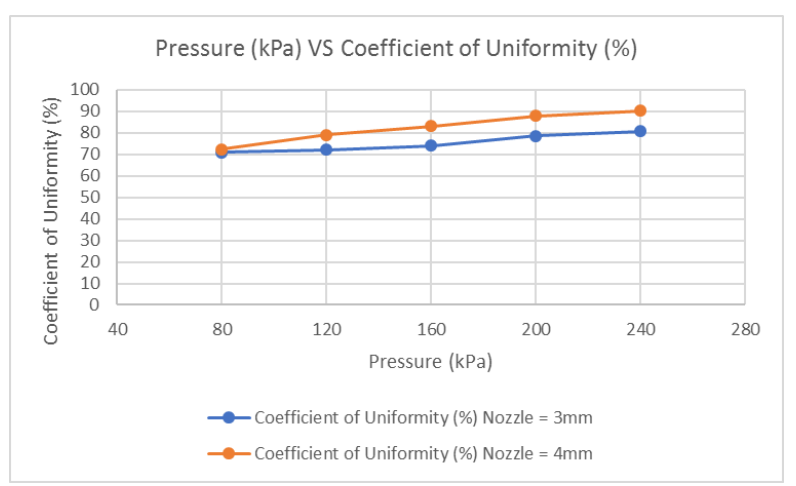

Fig. 15: Coefficient of Uniformity at Riser Height of $1.25 \mathrm{~m}$.

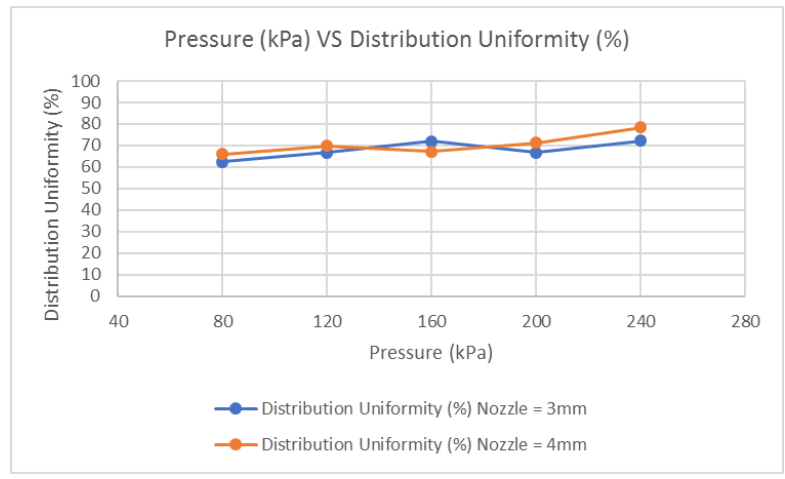

Fig. 12: Distribution Uniformity at Riser Height of $0.75 \mathrm{~m}$.

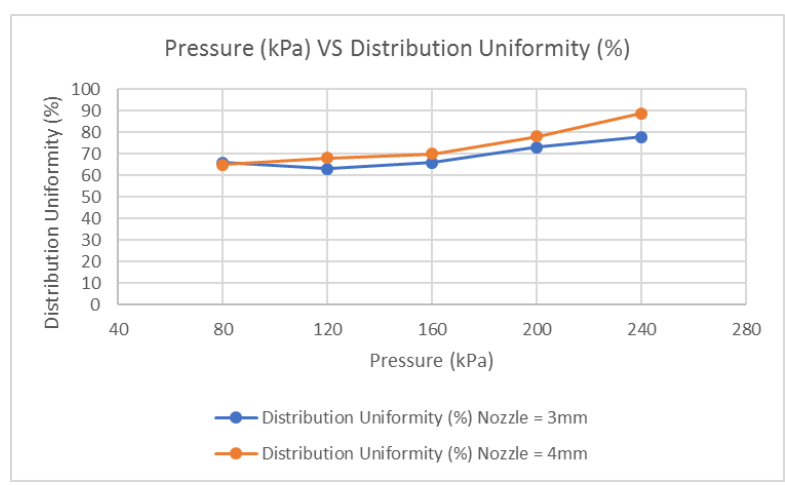

Fig. 14: Distribution Uniformity at Riser Height of $1.00 \mathrm{~m}$.

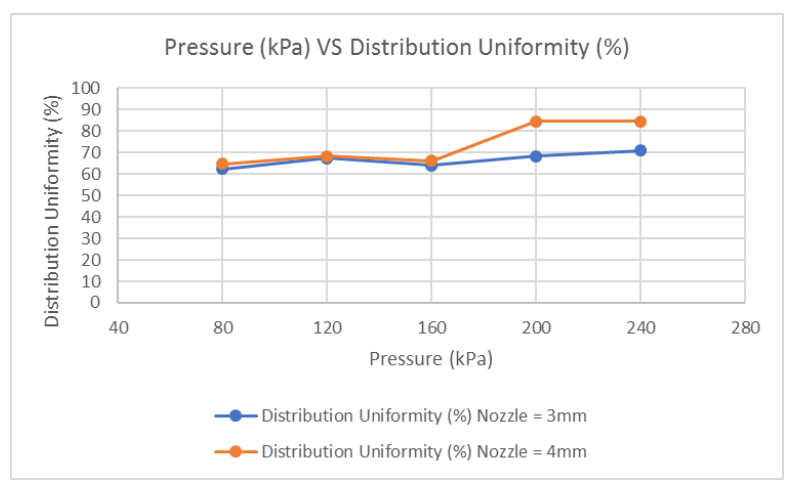

Fig. 16: Distribution Uniformity at Riser Height of $1.25 \mathrm{~m}$. 
Citation: Suhaimi Hassan, et al., 2018. Experimental Study on Irrigation Uniformity Using Low Pressure Single Set Sprinkler System. Journal of Applied Sciences Research., 14(3): 1-5.

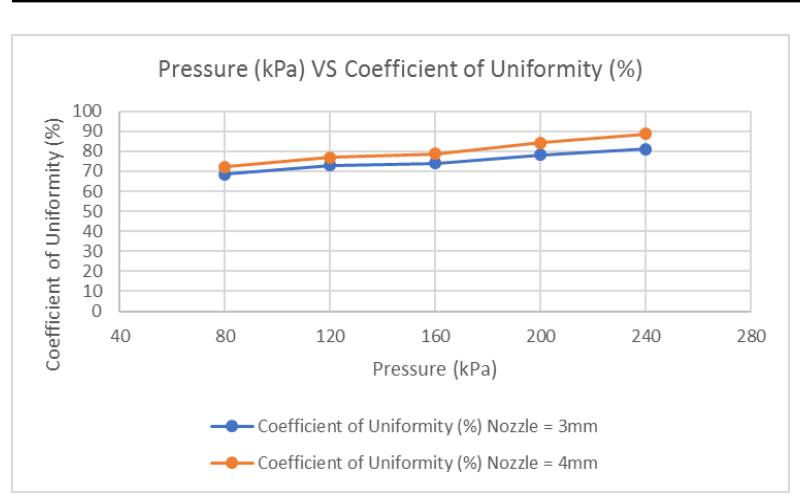

Fig. 17: Coefficient of Uniformity at Riser Height of 1.50 .

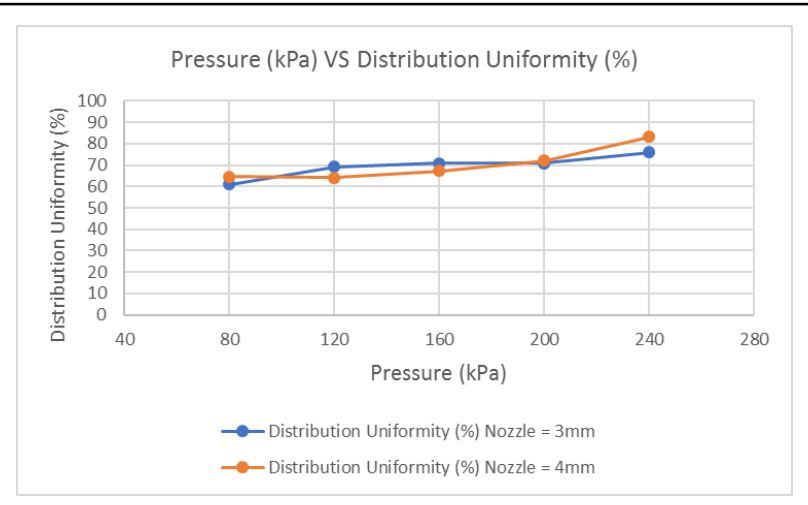

Fig. 18: Distribution Uniformity at Riser Height of $1.50 \mathrm{~m}$.

Based on the $\mathrm{CU}$ graphs plotted over the operating pressure as shown in presented Figures, some observation can be made to see where the optimum design that yield the best result from the variation of parameters used. The best result of the Coefficient of Uniformity (CU) can be obtained at operating pressure of 240 $\mathrm{kPa}$, riser height of $1.00 \mathrm{~m}$ and $4 \mathrm{~mm}$ nozzle diameter, where the value is $91.67 \%$. while the lowest value of CU $65.63 \%$ is obtained at operating pressure of 80 $\mathrm{kPa}$, riser height of $0.75 \mathrm{~m}$ and $3 \mathrm{~mm}$ nozzle diameter.

For the Distribution Uniformity (DU) the peak value obtained is $88.89 \%$ and the lowest value is $60.38 \%$. For the peak value, it occurs at pressure $240 \mathrm{kPa}$, riser height of $1.00 \mathrm{~m}$ and $4 \mathrm{~mm}$ nozzle diameter while for the lowest value it seems to occur at operating pressure of $160 \mathrm{kPa}$, riser height of $0.5 \mathrm{~m}$ and $3 \mathrm{~mm}$ nozzle diameter.

For most of the result plotted in the following graphs, the Coefficient of Uniformity (CU) and Distribution Uniformity (DU) increased as the operating pressure, riser height and nozzle diameter are being increased. Montero et al. (2000) also reported that the uniformity coefficient increased with increase of riser height above the ground. For some reason, the result for $\mathrm{CU}$ and DU are slight fluctuation when the operating pressure and riser height are increasing. There might be some reasons that may cause this case and one of them might be the wind drift which cause the wind velocity is not constant when experiment is bin conducted. As what has been reported by Yacoubi et al [10], the water distribution uniformity, CU and DU decreased with increase of wind velocity.

Therefore, the peak result for each CU and DU are both in agreement with what is being reported by Osman et al. [11] who have mentioned that the best sprinkler application basically need to achieve $85 \%$ of coefficient of uniformity (CU) and at least $80 \%$ of distribution uniformity of low quarter (DU).

According to the result obtained, the best performing sprinkler can be seen to be happen at the operating pressure of $240 \mathrm{kPa}$, riser height of $1.25 \mathrm{~m}$ with 4 $\mathrm{mm}$ nozzle diameter since these parameter combinations give the highest percentage of CU and DU which is $90.29 \%$ and $84.57 \%$. For the wetted diameter, it is able to create up to $11.88 \mathrm{~m}$. Therefore, this combination of parameters can be considered as the most appropriate and economically with wide wetted diameter and high CU and DU percentage in order to meet the objective of this experimental study.

5. Conclusion:

Based on the result obtained for this experimental study, the variation of the water distribution uniformity and wetted diameter obtained are basically depend on the combination of all three parameters that are being studied. However, there are some slight deviation on the graphs obtained and that deviations may be due to human errors, change in wind speed and instrumental errors.

For this experiment, the sprinkler irrigation system was tested at five difference operating pressures of $80 \mathrm{kPa}, 120 \mathrm{kPa}, 160 \mathrm{kPa}, 200 \mathrm{kPa}$ and $240 \mathrm{kPa}$ which are considered in range of low pressure system. Five different riser heights used for this experiment which are at $0.50 \mathrm{~m}, 0.75 \mathrm{~m}, 1.00 \mathrm{~m}, 1.25 \mathrm{~m}$ and 1.50 $\mathrm{m}$. The other parameter is nozzle diameter that is split to two different diameter which is $3 \mathrm{~mm}$ and $4 \mathrm{~mm}$.

From the observation made, the most optimum working pressure was at $240 \mathrm{kPa}$ since at this state, it can produce the largest wetted diameter. Wetted diameter is increased when the operating pressure and riser height are being increased but decrease when the nozzle diameter is increased from $3 \mathrm{~mm}$ to $4 \mathrm{~mm}$. While for the water distribution uniformity, the percentage of $\mathrm{CU}$ and $\mathrm{DU}$ is at peak value when the operating pressure is at $240 \mathrm{kPa}$ where the riser height is in range of $1.00 \mathrm{~m}$ to $1.25 \mathrm{~m}$ for both nozzle diameter. Though, at $3 \mathrm{~mm}$ nozzle diameter for this condition, the minimum requirement for CU and DU percentage cannot be achieved, only at $4 \mathrm{~mm}$ nozzle diameter the percentage of CU and DU can be successfully achieved with acceptable wetted diameter.

Therefore, as the objective of this experiment is to propose the most applicable sprinkler irrigation system for the industry, it can be said that the sprinkler is at its perfect operating system when the pressure is at $240 \mathrm{kPa}$, riser height is at $1.25 \mathrm{~m}$ and the nozzle diameter is $4 \mathrm{~mm}$ diameter. At these operating parameters, the result obtained for wetted diameter, Coefficient of Uniformity (CU) and Distribution Uniformity (DU) is $11.88 \mathrm{~m}, 90.29 \%$ and $84.57 \%$ respectively.

\section{REFERENCES}

[1] Carrión, P., J.M. Tarjuelo, J. Montero, 2001. SIRIAS: A simulation model for sprinkler irrigation. I. Description of model. Irrigation Science, 20 (2): $73-84$.

[2] Keller, J., R.D. Bliesner, 1990. Sprinkler and trickle irrigation. Van Nestrand Reinhold. New York.

[3] Playán, E., R. Salvador, J.M. Faci, N. Zapata, A. Martinez-Cob, I. Sanchez, 2005. Day and night wind drift and evaporation losses in sprinkler solid-sets and moving laterals. Agricultural Water Management, 76(3): 139-159.

[4] Lecina, S., E. Playan, D. Isidoro, F. Dechmi, J. Causape, J.M. Faci, 2005. Irrigation evaluation and simulation at the Irrigation.

[5] Tarjuelo, J.M., J. Montero, F.T. Honrubia, J.J. Ortiz, J.F. Ortega, 1999. Analysis of uniformity of sprinkler irrigation in a semi-arid area. Agricultural Water Management, 40: 315-331.

[6] Pair, C.H., D.C. Larsen and R.A. Kohl, 1975. Solid set sprinkler systems. University of Idaho, College of Agriculture, USA.

[7] Israelsen, O.W., V.E. Hansen and G.E. Stringhamm, 1962. Irrigation Principles and Practices 4th Edition, John Wiley and Sons, Inc. New York, USA.

[8] Christiansen, J. E. 1942. Irrigation by Sprinkler. California Agricultural Experiment Station. Bulletin, 670.

[9] Merriam, J.L. and J. Keller, 1978. Farm irrigation system evaluation: A guide for management, Dept. of Agricultural and Irrigation Engineering, Utah State Univ., Logan, Utah.

[10] Yacoubi, S., K. Zayani, A. Slatni, E. Playan, 2012. Assessing sprinkler irrigation performance using field evaluations at the Medjerda Lower Valley of Tunisia. Engineering, 4: 682-691.

[11] Osman, M., S.B. Hassan and K.W. Yusof, 2014. Effect of Low Pressure on Irrigation Uniformity of Solid Set Sprinkler Irrigation System. Applied Mechanics and Materials. (Vol. 567, pp. 26-31). Trans Tech Publications. 